\title{
Study of knowledge, attitude and acceptance of PPIUCD in antenatal mothers
}

\author{
Pradeep MR, Nayana DH \\ Correspondence: Dr Nayana DH, Assistant professor Department of OBG, Rajarajeshwari \\ medical college, Bangalore, Karnataka; Email - majormrp@gmail.com
}

Distributed under Attribution - NonCommercial - Share Alike 4.0 International (CC BY-NC-SA 4.0)

\begin{abstract}
Objectives: To find out the knowledge attitude and acceptance of post partum intrauterine contraceptive device (PPIUCD) among antenatal mothers. Methodology: This is an observational study to assess knowledge, attitude and acceptance of PPIUCD by antenatal mothers with family members by pre counseling and post counseling questionnaire. Results: A total of 137 antenatal mothers were studied from October 2018 to December 2018. Number of primi and multigravida were almost same in the study. Prior knowledge regarding PPIUCD was only in $15.3 \%$. About $51.8 \%$ accepted for PPIUCD after counseling. Most common reason in $66.7 \%$ for non acceptance was fear of complications. Conclusion: Knowledge on PPIUCD of our antenatal mothers is poor. Counseling of antenatal women and their families is helpful for high acceptance of PPIUCD.
\end{abstract}

Keywords: PPIUCD, primigravida, multigravida, counseling.

In current scenario population explosion is a most important problem in India. Recent study showed that almost 48.1 million pregnancies in India were unintended $^{1}$. To control unwanted pregnancies post partum IUCD insertion is an excellent method as it helps in spacing and avoiding unplanned pregnancies. In India $65 \%$ women in first year after delivery have an unmet need of family planning ${ }^{2}$. PPIUCD is a long term reversible safe, feasible and cost effective method of contraception which avoids unintended pregnancies ${ }^{3}$. Spacing of pregnancies reduces abortion rate, preterm births, low birth weight babies, intrauterine deaths, and postpartum hemorrhage, which in turn decrease in the maternal morbidity and mortality and infant mortality rate ${ }^{4}$.
Ministry of health and family welfare, Government of India launched provision of PPIUCD for women in 2010, and several training programmers and camps were conducted for its awareness ${ }^{5}$. But still PPIUCD insertion is not accepted widely as a method of temporary contraception. This study was undertaken to evaluate factors for knowledge attitude and acceptance of post partum IUCD in antenatal mothers at Chamarajanagar Institute of Medical Sciences, Chamarajanagar.

\section{Methodology}

This was an observational study from October 2018 to December 2018. All antenatal women attending outpatient department and coming for delivery in latent phase of labor were included in the study. Pre counseling and post counseling questionnaire was given to assess knowledge,

Received: $11^{\text {th }}$ March 2019. Accepted: $26^{\text {th }}$ May 2019.

Pradeep MR, Nayana DH. Study of knowledge, attitude and acceptance of PPIUCD in antenatal mothers. The New Indian Journal of OBGYN. 2019; 6(1): 42-4. 
attitude and acceptance of PPIUCD. Questionnaire was given to antenatal mothers along with their family (husband, mother in law). Questionnaire was printed in English / local language. Study was analyzed by

Table 4: Reasons for nonacceptance of PPIUCD appropriate statistical analysis.

\section{Results}

A total of 137 antenatal mothers attending to outpatient department and in latent labor during October 2018 to December 2018 were included in the study. Most

Table 1: Distribution of educational status and age of antenatal mothers and husbands

\begin{tabular}{llll}
\hline Variables & & $\begin{array}{l}\text { Antenatal } \\
\text { mothers(No) }\end{array}$ & $\begin{array}{l}\text { Husbands } \\
\text { (No) }\end{array}$ \\
\hline Education & 1-7 standard & 16 & 27 \\
& 8-10 standard & 78 & 62 \\
& $>10$ standard & 43 & 46 \\
Age in & Illiterate & Nil & 2 \\
years & $18-25$ & 96 & 57 \\
& $26-30$ & 41 & 62 \\
& $>30$ & nil & 18 \\
\hline
\end{tabular}

of the couples in our study were studied upto secondary school, able to read and write and understand regarding contraception. Couples in this study were young and eligible (Table 1). In our study most of them were house

Table 2: Showing various factors in relation to PPIUCD counseling

\begin{tabular}{|c|c|c|}
\hline \multicolumn{2}{|c|}{ Factors in the study } & Numbers \\
\hline \multicolumn{2}{|c|}{ Home maker } & 120 \\
\hline \multicolumn{2}{|c|}{ Working women } & 17 \\
\hline \multirow[t]{3}{*}{ Gravida } & 1 & 74 \\
\hline & 2 & 54 \\
\hline & 3 & 09 \\
\hline \multirow{2}{*}{\multicolumn{2}{|c|}{ Counseling during antenatal period }} & 103 \\
\hline & & 34 \\
\hline
\end{tabular}

Table 3: Knowledge regarding PPIUCD and its acceptance

\begin{tabular}{|c|c|c|c|c|c|}
\hline Variables & Primigravida & Gravida 2 & Gravida 3 & Percentage & counseling to antenatal mothers \\
\hline Prior knowledge regarding & & & & & and their families. Similar \\
\hline PPIUCD present & 12 & 09 & Nil & $21(15.3 \%)$ & observation is seen in Sebastian \\
\hline No prior knowledge on & & & & & MP et al ${ }^{6}$. \\
\hline $\begin{array}{l}\text { PPIUCD } \\
\text { Accentance of PPIUCD after }\end{array}$ & 62 & 45 & 09 & $116(84.6 \%)$ & Acceptance rate of PPIUCD \\
\hline counseling & 38 & 26 & 07 & $71(51.8 \%)$ & is almost same of $51 \%$ and $52 \%$ \\
\hline Non-acceptance of PPIUCD & 36 & 28 & 02 & $66(48.2 \%)$ & in primi and multigravida \\
\hline
\end{tabular}


acceptance of PPIUCD is high with $65.1 \%$ in multigravida compared to primigravida, on contrary high acceptance of $69 \%$ is seen in primigravida in Agarwal et $\mathrm{al}^{8}$. A significant rise of $51.8 \%$ from $15.3 \%$ in acceptance rate of PPIUCD was observed after effective counseling with antenatal mothers and their families in our study, same has been observed in Sebastian MP et $\mathrm{al}^{6}$. Even after effective counseling by doctor and counselor, most common reason for non acceptance of PPIUCD is because of fear of complications from PPIUCD. This shows that a lot of publicity from Television, radio, news paper, ASHA (accredited social health activist) workers, and educational campaign is needed to accept this method in large. On the other hand our study showed that most of multigravida of $81.5 \%$ inclined towards permanent sterilization. Even $51.4 \%$ of primigravida were happy with one child norm.

\section{Conclusion}

Knowledge on PPIUCD of our antenatal mothers is poor. Counseling of antenatal women and their families is helpful for high acceptance of PPIUCD. Even after effective counseling, common reason for non acceptance of PPIUCD is because of fear of complications. Repeated counseling and a lot of publicity from media like Television, radio, news paper, ASHA workers, and educational campaign regarding PPIUCD is needed to remove the fear on PPIUCD and for its acceptance.

\section{Conflict of interest: None. Disclaimer: Nil.}

\section{References}

1.Singh S, Shekar C, Acharya R, Moore AM, Stillman M, Pradhan M, et al. Incidence of abortion and unintended pregnancy in India - 2015. Lancet Glob Health. 2018; 6 : e111-20.
2.Ministry of Health and Family Welfare. Postpartum IUCD reference manual. New Delh: Family planning division ministry of health and family welfare; 2010.

3.Bedi PK, Guliani MS, Bala S. A prospective study of assess the safety and explosion rate of cuT380A in immediate post partum period during cesarean section. Int $\mathrm{J}$ Reprod Contracept Obstet Gynecol. 2016 Sept: 5(9): 319295

4.Majhi AK. Importance of PPIUCD in the perspective of present Indian population scenario. Indian Journal of perinatology and reproductive Biology. 2012: 2(2): 5-7.

5.Gadre SS, Ahirwar R. Level of acceptance of IUCD insertion in Indian women - a cross sectional mixed research from central India. Int J Reprod Contracept Obstet Gynecol. 2015; 4(4):1079-85

6.Sebastian MP, Khan ME, Kumari K, Idnani R. Increasing postpartum contraception in rural india : evaluation of a community based behavior change communication intervention. International perspectives on sexual and Reproductive Health. 2012; 38(2); 68-77.

7.Grimes D, Lopez LM, Schulz KF, Stanwood NL. Immediate post-partum insertion of intrauterine devices. Cochrane Database Syst Rev. 2010;12: CD 003036.

8.Agarwal N, Gupta M, Sharma A, Arora R. Antenatal counseling as a tool to increase acceptability of postpartum intrauterine contraceptive device insertion in a tertiary care hospital. Int J Reprod, Contracept Obstet and Gynecol. 2015 Aug: 4(4);1137-41.

Pradeep MR ${ }^{1}$, Nayana DH $^{2}$
${ }^{1}$ Associate professor, Department of OBG
Chamarajanagar Institute of medical sciences,
Chamarajanagar, Karnataka; ${ }^{2}$ Assistant professor
Department of OBG, Rajarajeshwari medical college
Bangalore, Karnataka

